\title{
Genesis of the 2014-2016 El Niño events
}

\author{
LIAN Tao ${ }^{1}$, CHEN DaKe ${ }^{1 *} \&$ TANG YouMin ${ }^{1,2}$ \\ ${ }^{1}$ State Key Lab of Satellite Ocean Environment Dynamics, Second Institute of Oceanography, Hangzhou 310012, China; \\ ${ }^{2}$ Environmental Science and Engineering, University of Northern British Columbia, Prince George BC V2N 4Z9, Canada
}

Received November 8, 2016; accepted January 10, 2017; published online February 27, 2017

\begin{abstract}
The 2015/2016 El Niño was one of the strongest El Niño events in history, and this strong event was preceded by a weak El Niño in 2014. This study systematically analyzed the dynamical processes responsible for the genesis of these events. It was found that the weak 2014 El Niño had two warming phases, the spring-summer warming was produced by zonal advection and downwelling Kelvin waves driven by westerly wind bursts (WWBs), and the autumn-winter warming was produced by meridional advection, surface heating as well as downwelling Kelvin waves. The 2015/2016 extreme El Niño, on the other hand, was primarily a result of sustained zonal advection and downwelling Kelvin waves driven by a series of WWBs, with enhancement from the Bjerknes positive feedback. The vast difference between these two El Niño events mainly came from the different amount of WWBs in 2014 and 2015. As compared to the 1982/1983 and 1997/1998 extreme El Niño events, the 2015/2016 El Niño exhibited some distinctive characteristics in its genesis and spatial pattern. We need to include the effects of WWBs to the theoretical framework of El Niño to explain these characteristics, and to improve our understanding and prediction of El Niño.
\end{abstract}

Keywords El Niño, WWBs, Upper ocean heat content

Citation: Lian T, Chen D K, Tang Y M. 2017. Genesis of the 2014-2016 El Niño events. Science China Earth Sciences, 60: 1589-1600, doi: 10.1007/s11430$016-8315-5$

\section{Introduction}

The El Niño-Southern Oscillation (ENSO) is the most energetic short-term climate variability on the Earth (McPhaden, 1999). It is characterized by a quasi-periodic warming and cooling of sea surface temperature (SST) in the central-eastern equatorial Pacific every 2-7 years (Rasmusson and Carpenter, 1982). The warming and cooling events are termed El Niño and La Niña, respectively. Because of its tremendous global impact (Philander, 1990; Lian et al., 2014a; Sun et al., 2015; Lian and Tang, 2017; Wang et al., 2016; Zhang et al., 2017), ENSO has been a focus of oceanic and atmospheric research since 1980s, and significant progress has been made in observing, understanding and predicting ENSO (Chen et al., 1995, 2004; Neelin et al., 1998; McPhaden et al., 1999; Chen and Cane 2008). However, there are still many un-

* Corresponding author (email: dchen@sio.org.cn) solved problems. In particular, the unusual 2014-2016 El Niño events has raised serious challenges to the classic ENSO theory and the model predictions based on such theory.

The classic theory suggests that the state of ENSO depends on the variation of the equatorial upper ocean heat content (Jin, 1997a, 1997b) and the Bjerknes feedback (Bjerknes, 1969). When the equatorial upper ocean heat content is high, the thermocline in the eastern equatorial Pacific is deep and thus the cooling effect of upwelling is weak, causing a warm anomaly in sea surface temperature (SST). This anomaly can be further amplified by the Bjerknes feedback and eventually lead to an El Niño. The situation is just the opposite when the equatorial upper ocean heat content is low, as the relatively shallow thermocline and strong upwelling cause a cold anomaly, which evolves into a La Niña through the Bjerknes feedback. Here the Bjerknes feedback refers to the positive feedback between the SST anomaly and the zonal wind anomaly, which, according to wind-driven ocean dynamics, can be 
further divided into the "zonal advection feedback" and the "thermocline feedback" (An and Jin, 2001).

Beginning in winter 2013, the upper ocean heat content in the equatorial Pacific increased rapidly, reaching a magnitude larger than that preceding the 1982/1983 super El Niño (http://www.pmel.noaa.gov/tao/elNiño/wwv). In addition, the eastward current anomalies increased from January 2014 through March 2014. In accordance with the classic ENSO theory, many models predicted in spring 2014 a strong or even extreme El Niño to occur later in the year (http:/www.cpc.ncep.noaa.gov/products/GODAS/ ocean_briefing_gif/global_ocean_monitoring_2014_05.ppt). There were indeed warm SST anomalies in the central and eastern equatorial Pacific during 2014, but they did not evolve into a sustained strong warming. On the other hand, the equatorial upper ocean heat content rapidly decreased starting from summer 2014 (http://www.pmel.noaa.gov/tao/elNiño/ wwv). In February 2015, the climate models predicted that there was only a $50-60 \%$ possibility for an El Niño to occur at the end of 2015, and many of them even predicted a natural or a La Niña state (http://www.cpc.ncep.noaa.gov/products/GODAS/ocean_briefing_gif/global_ocean_monitoring 2015_03.ppt). However, to our surprise again, an extreme El Niño took place from autumn 2015 through spring 2016.

The failure to predict the 2014-2016 El Niño events forces us to rethink ENSO dynamics. It is clear that the occurrence and magnitude of ENSO events are not solely determined by the variation of the equatorial upper ocean heat content. Observations have shown that almost every El Niño in recent history was closely associated with the westerly wind bursts (WWBs) (McPhaden, 2004; Lian et al., 2014b; Chen et al., 2015), a type of high-frequency atmospheric perturbations over the western-central tropical Pacific (Harrison and Vecchi, 1997; Fu and Huang, 1997; Vecchi and Harrison, 2000; Yan and Zhang, 2002; Seiki and Takayabu, 2007). The WWBs could warm the central equatorial Pacific SST by advecting warm water eastward from the western Pacific warm pool, and produce SST warming in the eastern equatorial Pacific by generating downwelling Kelvin waves (McPhaden et al., 1988, 1992; McPhaden, 2004; Lian et al., 2014b; Fedorov et al., 2015). It was also suggested that WWBs could warm the equatorial Pacific by increasing the nonlinear interaction between surface wind and the SST anomaly (Rong et al., 2011). Therefore, WWBs may play a fundamental role in El Niño genesis and development. Moreover, WWBs could also have strong influence on El Niño diversity (Chen et al., 2015). Such diversity is generally characterized by three types of El Niño: the relatively weak warm pool El Niño in the western-central equatorial Pacific (Fu et al., 1986; Larkin and Harrison, 2005; Ashok et al., 2007; Kug et al., 2009; Lian and Chen, 2012), the canonical El Niño spanning the central-eastern equatorial Pacific (Rasmusson and Carpenter,
1982), and the extreme El Niño in the east with extraordinary magnitude but fewer occurrence.

Chen et al. (2015) further pointed out that the magnitude and the type of an El Niño depends on the interplay between the WWBs and the upper ocean heat content. When WWBs occur at a state of low upper ocean heat content, only the warm advection mechanism kicks in to produce a warm pool El Niño. When WWBs occur at a state of high upper ocean heat content, the combined effects of the warm advection and the thermocline feedback lead to a canonical El Niño. When the integrated WWB intensity and the upper ocean heat content are both very high, the SST anomaly in the eastern equatorial Pacific is largely enhanced by the local thermocline feedback to generate an extreme El Niño. Based on such a reason, Chen et al. (2015), Li et al. (2015) and Zhang and Li (2015) argued that the lack of WWBs in summer 2014 is the main reason for the absence of a strong 2014 El Niño. Using an ocean general circulation model, Menkes et al. (2014) further showed that the SST anomaly in the eastern equatorial Pacific could be significantly enhanced at the end of 2014 if the strong WWBs that occurred in 1997 (McPhaden, 1999) were added to the forcing field. In addition, the enhanced trade wind associated with the SST cooling in the southeastern Pacific (Min et al., 2015) and the easterly wind surge occurring in the middle of 2014 (Liu et al., 2015; Hu and Fedorov, 2016) were also proposed as the reasons for the unexpectedly weak 2014 El Niño.

The present study analyzes the dynamical processes and mechanisms of the 2014-2016 El Niño events. In particular, we will explore the genesis of extreme El Niño by comparing the evolution of the 2015/2016 El Niño with the 1982/1983 and 1997/1998 extreme events. We will also show the inadequacy of the classic ENSO theory and suggest a possible way for improvement.

\section{Data and method}

The datasets used in this study include the daily surface wind from the National Centers for Environmental Prediction (NCEP) Reanalysis 2 (Kanamitsu et al., 2002) and the monthly ocean temperature, current, and surface heat flux provided by the NCEP Global Ocean Data Assimilation System (NCEP-GODAS) (Saha et al., 2006). The resolution of the surface wind is $2.5^{\circ}$ longitude $\times 2.5^{\circ}$ latitude, and the resolution for the NCEP-GODAS datasets is $1 / 3^{\circ}$ longitude $\times$ $1.0^{\circ}$ latitude. The period of data used is from January 1980 to March 2016. The linear trend and the climatological seasonal cycle are subtracted from the record to obtain the anomaly fields.

The upper ocean $(0-50 \mathrm{~m})$ average temperature is used to represent SST. The depth of the $20^{\circ} \mathrm{C}$ isotherm (D20) is used for the equatorial thermocline depth. The integral of the warm 
water volume (WWV) above D20 depth is used as the upper ocean heat content (Meinen and McPhaden, 2000). Following Lian et al. (2014b) and Chen et al. (2015), a WWB is defined as a zonal wind anomaly with a maximum speed of at least $7 \mathrm{~m} \mathrm{~s}^{-1}$, and a duration of 5 to 30 days during which anomalous speed exceeding $2 \mathrm{~m} \mathrm{~s}^{-1}$. Following Chen et al. (2015), the integration of WWBs over the equatorial Pacific $\left(120^{\circ} \mathrm{E}-80^{\circ} \mathrm{W}, 5^{\circ} \mathrm{S}-5^{\circ} \mathrm{N}\right)$, termed WWB Wind Measure, is used to scale the effect of WWB. The commonly used ENSO indices NINO3, NINO4, and NINO3.4 are SST anomalies averaged in the regions $\left(150^{\circ}-90^{\circ} \mathrm{W}, 5^{\circ} \mathrm{S}-5^{\circ} \mathrm{N}\right)$, $\left(160^{\circ} \mathrm{E}-150^{\circ} \mathrm{W}, 5^{\circ} \mathrm{S}-5^{\circ} \mathrm{N}\right)$ and $\left(170^{\circ}-120^{\circ} \mathrm{W}, 5^{\circ} \mathrm{S}-5^{\circ} \mathrm{N}\right)$, respectively.

The heat budget for an SST anomaly is (Jin et al., 2003):

$$
\begin{aligned}
\frac{\partial T}{\partial t}= & \left(-u^{\prime} \frac{\partial \bar{T}}{\partial x}-\bar{u} \frac{\partial T^{\prime}}{\partial x}-u^{\prime} \frac{\partial T^{\prime}}{\partial x}\right) \\
& +\left(-v^{\prime} \frac{\partial \bar{T}}{\partial y}-\bar{v} \frac{\partial T^{\prime}}{\partial y}-v^{\prime} \frac{\partial T^{\prime}}{\partial y}\right) \\
& +\left(-w^{\prime} \frac{\partial \bar{T}}{\partial z}-\bar{w} \frac{\partial T^{\prime}}{\partial z}-w^{\prime} \frac{\partial T^{\prime}}{\partial z}\right) \\
& +Q+\operatorname{Res},
\end{aligned}
$$

where, $T, u, v$ and $w$ denote the average ocean temperature, zonal velocity, meridional velocity and vertical velocity in the upper 50 meter, respectively. $Q$ and Res are the net surface heat flux and the residual term, respectively. The primes and bars denote the anomaly and the mean, respectively. The three parentheses on the right hand side of eq. (1) represent the changes of SST anomaly due to zonal, meridional, and vertical advections. We label the three terms in the first parenthesis as Z1, Z2, and Z3, those in the second parenthesis as
$\mathrm{M} 1, \mathrm{M} 2$, and M3, and those in the last parenthesis as V1, V2, and $\mathrm{V} 3$.

\section{Evolution of the 2014-2016 EI Niño events}

The 3-month running mean of the NINO3.4 index from January 1980 to March 2016 is given in Figure 1a. The SST anomaly here was above the $0.5^{\circ} \mathrm{C}$ threshold from April 2014 to March 2016, with a minimum in February 2015. The maximum NINO3.4 was $3.13^{\circ} \mathrm{C}$, larger than those during the $1997 / 1998 \mathrm{El}$ Niño $\left(3.12^{\circ} \mathrm{C}\right)$ and the $1982 / 1983 \mathrm{El}$ Niño $\left(2.57^{\circ} \mathrm{C}\right)$. However, for the NINO3 region further to the east, the maximum SST anomaly during the 2015/2016 El Niño was smaller than that of the 1997/1998 El Niño (Figure 1b). It is worth noting that unlike the other two extreme El Niño events, there was strong warming in the NINO4 region during the 2015/2016 El Niño (Figure 1c). The maximum SST anomaly there was $1.79^{\circ} \mathrm{C}$, larger than that occurred in the 2009/2010 El Niño, which was ranked as the strongest warm pool El Niño in history (Lee and McPhaden, 2010). In addition, the NINO4 anomaly peaked in September 2014 with a magnitude larger than the NINO3 and NINO3.4 anomalies at the same time. It is clear that the 2014-2016 El Niño events were not only strong and long-lasting, but also distinctively different from previous events in spatiotemporal variations.

Figure 2a displays the time-longitude evolution of the equatorial $\left(5^{\circ} \mathrm{S}-5^{\circ} \mathrm{N}\right) \mathrm{SST}$ anomaly from January 2014 to March 2016. The prolonged warming during this period can be roughly divided into six stages. The first warming (Stage 1) occurred in the western-central equatorial Pacific $\left(160^{\circ} \mathrm{E}-170^{\circ} \mathrm{W}\right)$ from February to May 2014 , with a maxi-
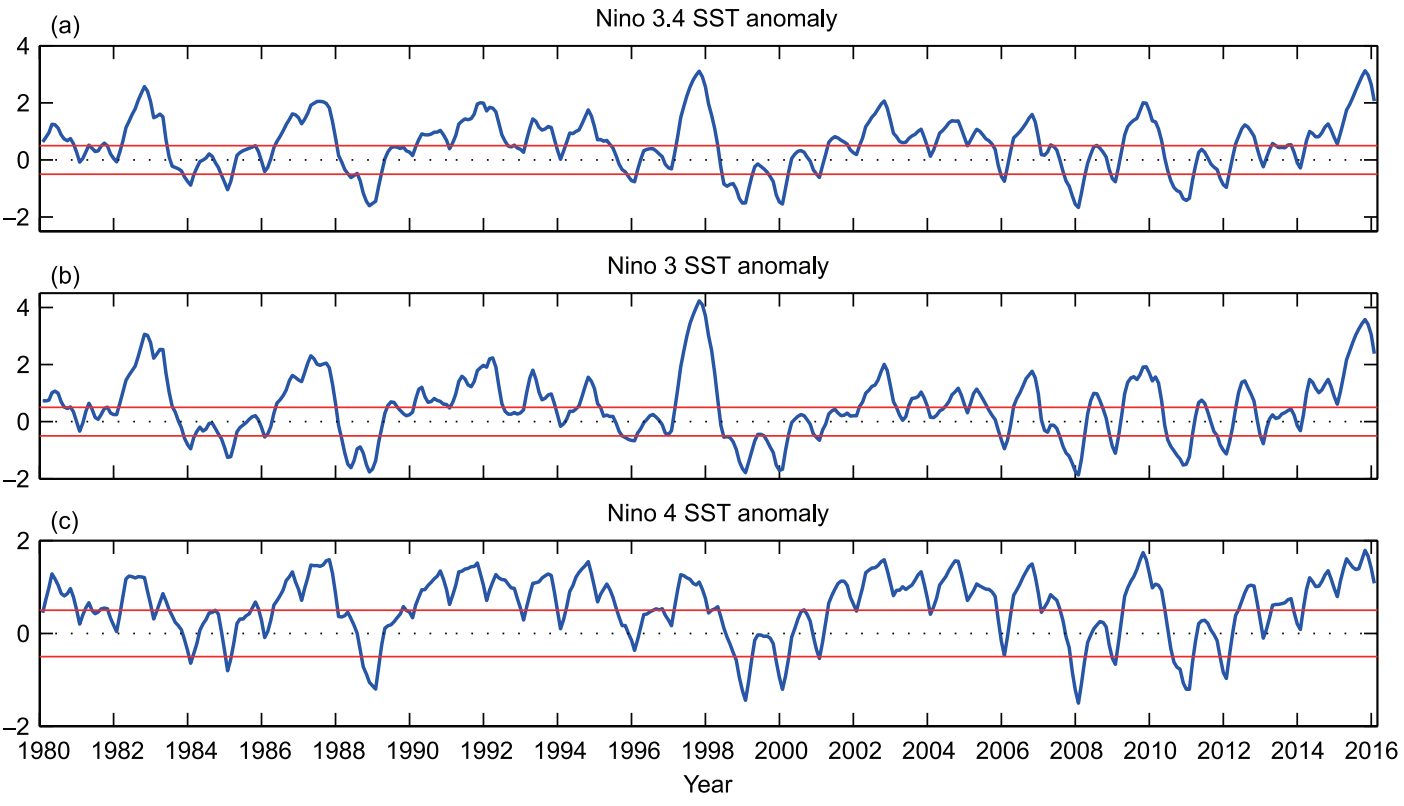

Figure 1 Three-month running mean SST anomaly averaged in NINO3.4 (a), NINO3 (b) and NINO4 (c) regions. Red solid lines denote thresholds of $0.5^{\circ} \mathrm{C}$ and $-0.5^{\circ} \mathrm{C}$, Unit is ${ }^{\circ} \mathrm{C}$. 

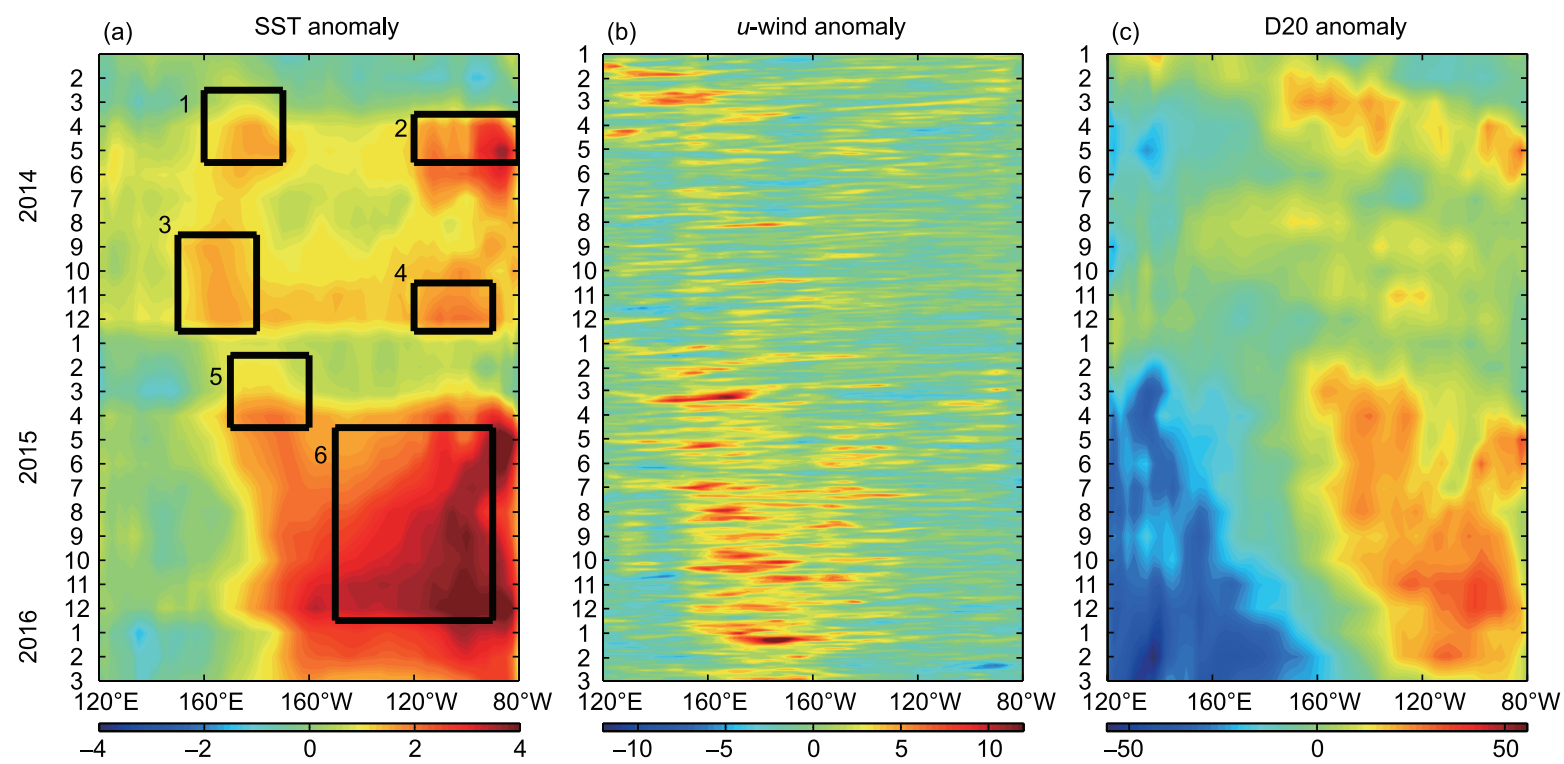

Figure 2 Longitude-time plots of equatorial $\left(5^{\circ} \mathrm{S}-5^{\circ} \mathrm{N}\right)$ (a) SST anomaly, (b) zonal wind anomaly, and (c) D20 anomaly from January 2014 to March 2016. The black boxes shown in (a) denote the six SST warming stages discussed in the text, which are also used to estimate the surface layer heat budget shown in Figure 3.

mum SST anomaly of $1.58^{\circ} \mathrm{C}$. The second warming (Stage 2) took place in the east $\left(120^{\circ}-80^{\circ} \mathrm{W}\right)$ from April to June 2014 , with a maximum anomaly reaching $3.62^{\circ} \mathrm{C}$, which however disappeared in August 2014 and did not evolve into a big El Niño. After that, another warming (Stage 3) occurred in the western region $\left(150^{\circ} \mathrm{E}-180^{\circ}\right)$ and slowly propagated eastward. Meanwhile, the eastern equatorial Pacific started to warm again (Stage 4), with a maximum SST anomaly of $2.05^{\circ} \mathrm{C}$ occurring in December 2014 in the region of $120^{\circ}-90^{\circ} \mathrm{W}$. The SST evolution in the early months of 2015 was somewhat similar to that of 2014, with a spring warming in the western-central equatorial Pacific (Stage 5), followed by a warming in the east. The difference is that these two warming centers merged in the following months and eventually evolved into a huge El Niño (Stage 6). The maximum SST anomaly at this stage was found near $100^{\circ} \mathrm{W}$, with a magnitude of $4.21^{\circ} \mathrm{C}$. Although this peak value was far less than that during the 1982/1983 and 1997/1998 El Niño events $\left(6.24^{\circ} \mathrm{C}\right.$ in March 1983 and 1998 near $80^{\circ} \mathrm{W}$ ), the warming area of the $2015 / 2016$ event was large and extended more to the west. This explains why the warming in the NINO3.4 region was the strongest during the 2015/2016 El Niño.

Previous studies suggested that the primary dynamical processes involved in El Niño development are the eastward advection by anomalous surface currents and the vertical advection induced by the thermocline variation (An and Jin, 2001). Figure $2 \mathrm{~b}$ and $\mathrm{c}$ shows the time-longitude evolution of the zonal wind anomaly and D20 anomaly from January 2014 to March 2016. The most distinct feature was the strong and frequent westerlies (WWBs) over the western-central equatorial Pacific in spring 2014 and during the entire year of
2015 (Figure 2b). The WWBs occurred over the region of $130^{\circ}-170^{\circ} \mathrm{E}$ in spring 2014 excited a group of strong downwelling Kelvin waves, as indicated by the eastward propagating thermocline anomalies (Figure 2c), which were probably responsible for the following warming in the eastern equatorial Pacific (Stage 2). There were no prominent WWBs in summer and autumn 2014, but a couple of short WWBs occurred in August and October near the dateline, which obviously excited some weak Kelvin waves (Figure $2 b$ and $c$ ) and might contribute to the subsequent warming in the eastern equatorial Pacific (Stage 4). In 2015, the frequent WWBs kept initiating downwelling Kelvin waves, as manifested by a continuum of the eastward propagation of the positive D20 anomalies, which surly favored the development of a strong El Niño event (Stage 6).

To analyze the mechanisms of the 2014-2016 El Niño events in more detail, Figure 3 shows the area-averaged surface layer heat budget for the 6 different warming stages (as indicated by the boxes in Figure 2). Note that the end of each stage is set at the time of the maximum SST anomaly, so that the heat budget in Figure 3 is for the growing phase of warming. At Stage 1, the main contributor to the warming was the zonal advection (Figure 3a), which was obviously due to the anomalous eastward currents driven by local WWBs (Figure 2b). Because the warming at this stage was in the western equatorial Pacific where the climatological thermocline is deep, the vertical advection term did not play a major role. The anomalous surface heat flux also made considerable contribution. At Stage 2, the warming was mainly due to the anomalous vertical advection that resulted from the downwelling Kelvin waves generated by the WWBs occurring at Stage 1 (Figure 3b). At Stage 3, unlike most of 

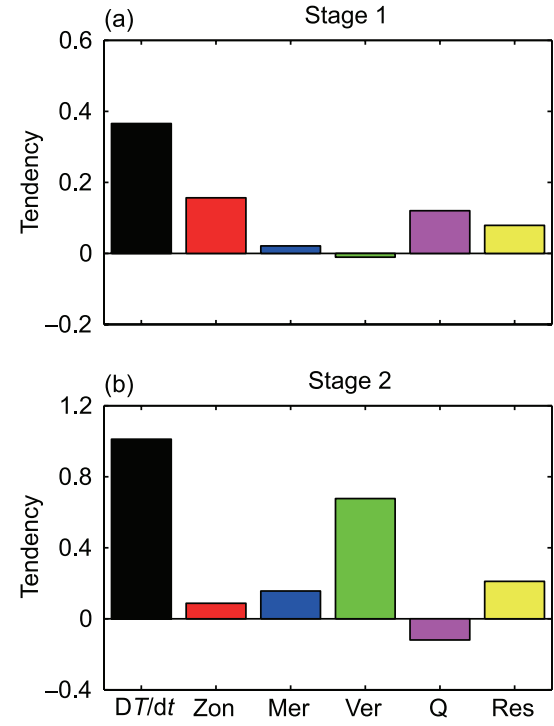

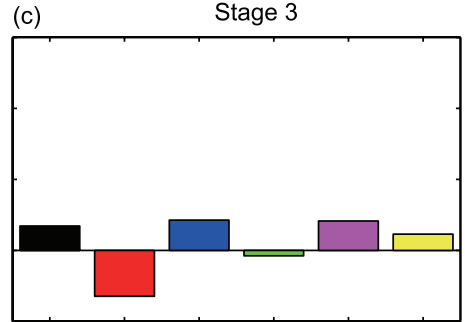

(d)

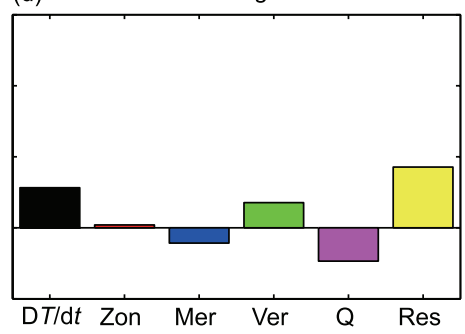

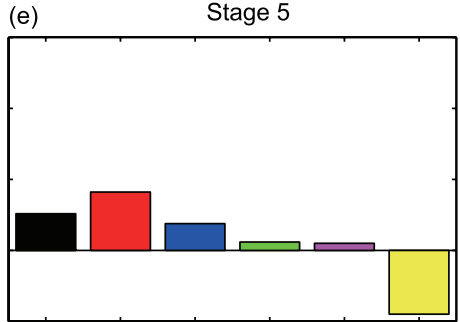

(f) Stage 6

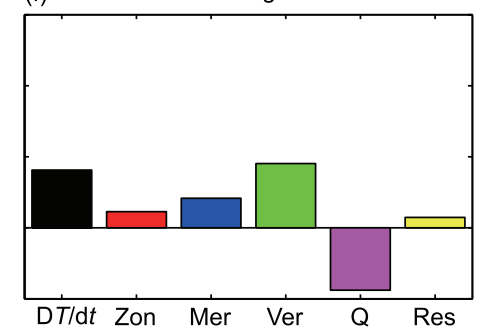

Figure 3 Area-averaged surface-layer heat budgets for the six warming stages in the 2014-2016 El Niño events. Red, blue, and green bars denote zonal, meridional, and vertical advection, respectively. Black, purple, and yellow are the total tendency, surface heating and residual term, respectively. The units for all terms are ${ }^{\circ} \mathrm{C} /$ month.

the central equatorial Pacific warming events, the zonal advection was suppressing instead of enhancing the warming (Figure 3c), probably because of the anomalous easterlies occurring at this stage (Figure 2b). The warming was mainly caused by the anomalous meridional advection and surface heat flux. At Stage 4, although the zonal and vertical advections were at work, the dominant player was the residual term (Figure 3d), which primarily represents the effects of the horizontal and vertical mixing. The warming at Stage 5 was similar to that at Stage 1, mainly due to the eastward warm advection driven by local WWBs (Figure 3e). Stage 6 was typical for the development of a major El Niño, when all advection terms were contributors to the warming, with the main player being the anomalous vertical advection induced by the thermocline deepening (Figure 3f). It is worth noting that the residual term accounts for a large part of the SST warming at Stage 4 and Stage 5, indicating that processes not explicitly expressed in eq. (1), such as eddies and turbulence, could play a significant role in the surface layer heat balance.

\section{Comparison of the extreme EI Niño events}

As shown above, the equatorial Pacific experienced several warming stages during the period of 2014-2016, which can be roughly divided into a weak El Niño from March 2014 to February 2015 and an extreme El Niño from March 2015 to March 2016. In this section, we try to elucidate the dynamics of the 2015/2016 El Niño by comparing it to the 1982/1983 and 1997/1998 extreme events. Figure 4a shows the evolution of the NINO3.4 SST anomaly for these three El Niño events. For the 2015/2016 El Niño, NINO3.4 became positive in March prior to the El Niño year (Year-1). For the
1982/1983 and 1997/1998 El Niño events, in contrast, positive anomalies did not occur till March of the El Niño year (Year 0). The growth rate of the positive SST anomalies is comparable for the 2015/2016 and the 1982/1983 El Niño events, but smaller for the 1997/1998 El Niño. However, since the NINO3.4 SST anomaly in March 2015 is greater than that in March 1997, the maximum NINO3.4 SST anomaly that occurred in November 2015 is slightly larger than the maximum anomaly during the 1997/1998 El Niño.

The evolution of the WWV anomaly during 2015/2016 El Niño was quite different as compared to that of the 1982/1983 and 1997/1998 El Niño events (Figure 4b). Except for two short periods of growth in January-March 2014 and July-August 2014, the WWV anomaly did not increase significantly during the 2015/2016 El Niño. In particular, the WWV anomaly was staying at a low level since January 2015 . In contrast, significant positive WWV anomalies were found in 1982 and 1997. This suggests that the upper ocean heat content was not a major player in the development of the 2015/2016 extreme El Niño. In other words, the classic recharge-discharge ENSO theory does not apply to the 2015/2016 El Niño. While the basin-averaged equatorial WWV anomaly was close to zero, the WWV in the eastern equatorial Pacific did show large positive anomalies in 2015 (Figure 2c), which played an important role in warming the eastern equatorial Pacific (Figure 3f). To evaluate the other basic process involved in El Niño development, the zonal advection, Figure 4c compares the evolution of the eastward current for the three El Niño events. The current magnitude during the 2015/2016 El Niño was comparable to that during the 1997/1998 El Niño and larger than that during 1982/1983 El Niño. Note that the eastward current increased rapidly in January-March 2014, 

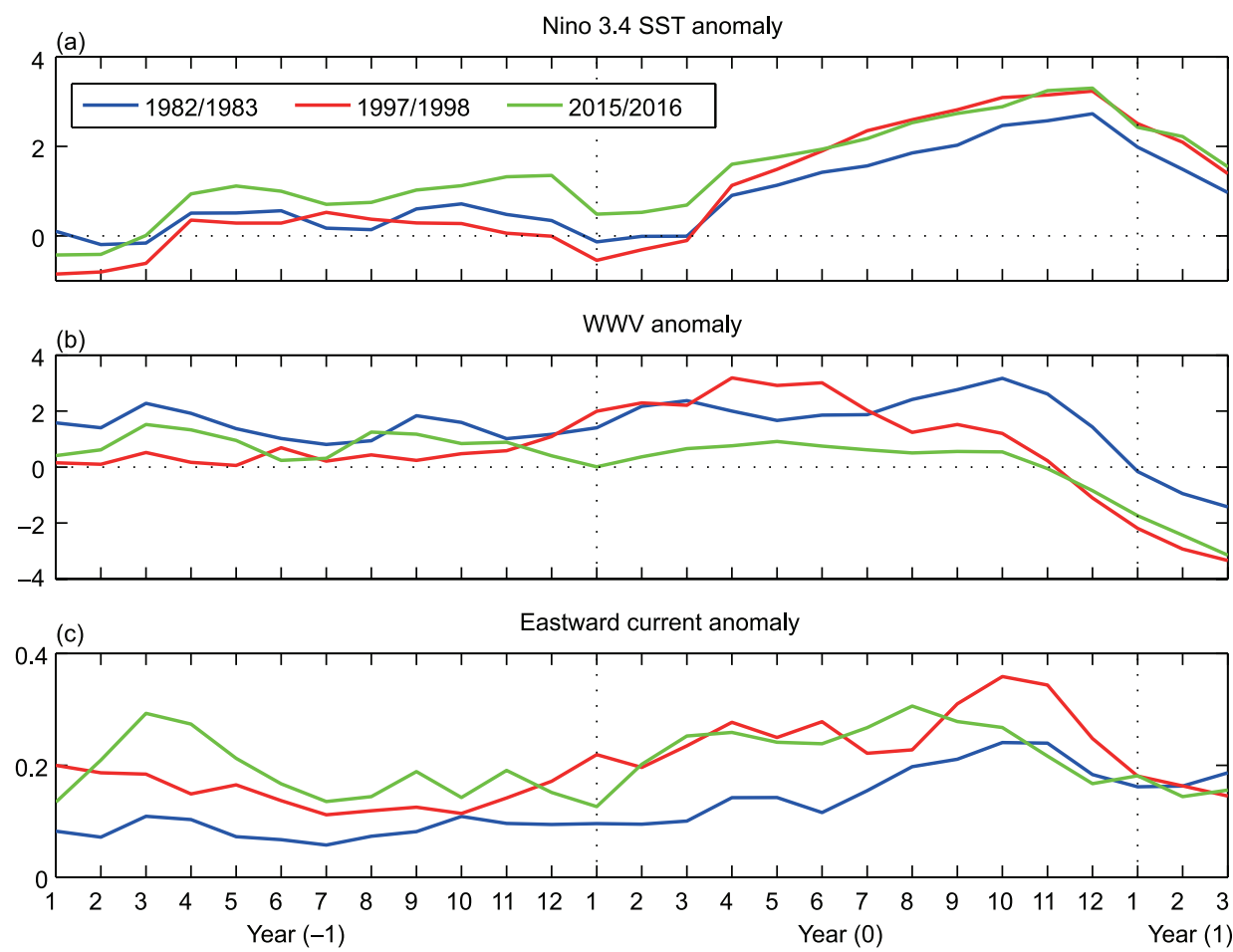

Figure 4 Evolution of (a) NINO3.4 SST anomaly $\left({ }^{\circ} \mathrm{C}\right)$, (b) WWV anomaly $\left(10^{14} \mathrm{~m}^{3}\right)$, and (c) eastward current $\left(\mathrm{m} \mathrm{s}^{-1}\right)$ in the equatorial Pacific during the 1983/1983 (blue lines), 1997/1998 (red lines) and 2015/2016 (green lines) El Niño events. Year (-1) and Year (1) denote the year before and after the El Niño year, respectively. Year (0) denotes the El Niño year.

apparently forced by WWBs, leading to the SST warming in the western-central equatorial Pacific in spring 2014 (Stage 1 in Figure 2a). The current decreased afterwards due to the absence of the WWBs.

Figure 5 compares the area-averaged heat budgets of the three El Niño events for two regions. In the NINO3.4 region (Figure $5 \mathrm{a}-\mathrm{c}$ ), consistent to above analysis, the growth rate of the SST anomaly during the 2015/2016 El Niño was comparable to that of the 1982/1983 El Niño but smaller than that of the 1997/1998 El Niño. The contribution of the zonal
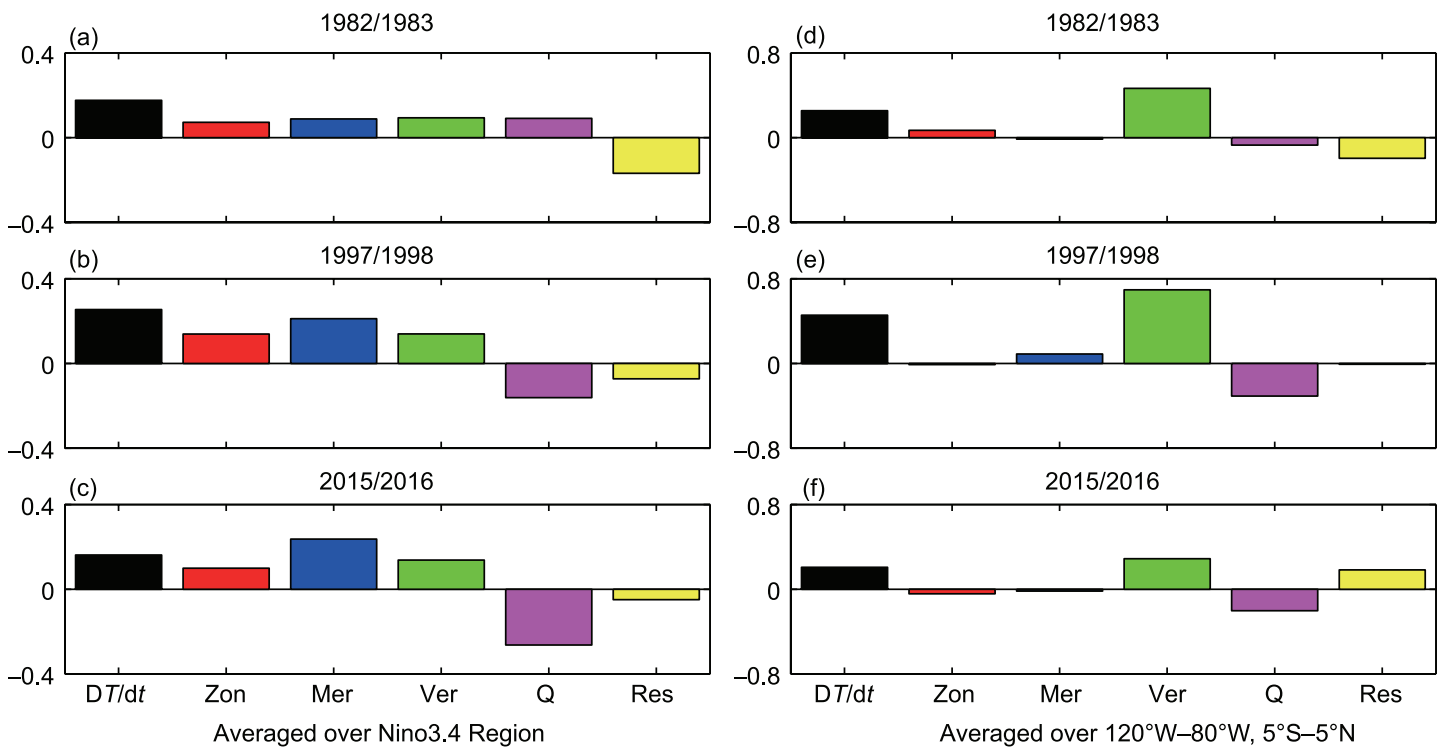

Figure 5 Surface-layer heat budgets in regions of NINO3.4 (left panel) and $\left(120^{\circ}-80^{\circ} \mathrm{W}, 5^{\circ} \mathrm{S}-5^{\circ} \mathrm{N}\right)$ (right panel) for the $1982 / 1983$ (upper row), $1997 / 1998$ (middle row), and 2015/2016 (bottom row) El Niño events. Red, blue, and green bars denote zonal, meridional, and vertical advection, respectively. Black, purple, and yellow are for total tendency, surface heating, and residual term, respectively. The units for all terms are ${ }^{\circ} \mathrm{C} / \mathrm{month}$. The budget is averaged over the region and over the El Niño year (from January to December). 
advection in 2015/2016 was larger than that in $1982 / 1983$ but smaller than that in 1997/1998. The vertical advection had the largest impact in 1997/1998 and the smallest in 1982/1983. The net surface heat flux exerted a significant cooling effect during the 2015/2016 event. In the eastern equatorial Pacific $\left(120^{\circ}-80^{\circ} \mathrm{W}, 5^{\circ} \mathrm{S}-5^{\circ} \mathrm{N}\right)$ region (Figure $\left.5 \mathrm{~d}-\mathrm{f}\right)$, because the D20 anomaly was relatively weak during the 2015/2016 El Niño, the vertical advection played a less significant role in SST warming as compared to the other two events. This also explains why the maximum SST anomaly during the 2015/2016 El Niño was not close to the South American coast where the thermocline feedback should be the strongest. It is worth noting that the net surface heat flux generally suppressed the SST warming during these El Niño events, but there was an exception in the NINO3.4 region during the $1982 / 1983$ event, when the heat flux had a warming effect (Figure 5a). This discrepancy may result from the data quality in early years.

To further explore the differences among the three extreme El Niño events, Figure 6 shows the components of the heat budget terms in eq. (1) for the NINO3.4 region. Jin et al. (2003) suggested that the nonlinear vertical advection term $\left(-w^{\prime} \frac{\partial T^{\prime}}{\partial z}\right)$ played a very important role in the development of the 1997/1998 extreme El Niño. However, we found that this nonlinear term had a cooling rather than warming effect during the 1997/1998 and 2015/2016 El Niño events (V3 in Figure 6). It was further found that the anomalous vertical velocity in the NINO3.4 region was downward (negative velocity) instead of upward (positive velocity) during these two events (not shown). Because the anomalous vertical temperature gradient was negative (the temperature anomaly in the subsurface was warmer than the surface temperature anomaly) in the eastern equatorial Pacific, the nonlinear vertical advection term thus suppressed the local SST anomaly. Conversely, since the anomalous vertical velocity was positive (negative) during the 1982/1983 (1997/1998 and 2015/2016) El Niño, the first component of the vertical advection $\left(-w^{\prime} \frac{\partial T^{\prime}}{\partial z}\right)$ was negative during the $1982 / 1983$ event but positive during the 1997/1998 and 2015/2016 events (V1 in Figure 6). The discrepancies between our results and that of Jin et al. (2003) may be due to different datasets used and to the large uncertainty in the vertical velocity calculations in these datasets. The vertical advection term related to the climatology upwelling $\left(-\bar{w} \frac{\partial T^{\prime}}{\partial z}\right)$ made a significant positive contribution during all three extreme events (V2 in Figure 6), indicating that the thermocline feedback plays an essential role in the development of the extreme El Niño events.

Figure 6 also explains why the zonal advection did not have a more significant effect on the NINO3.4 SST warming during the 2015/2016 event as compared to the 1982/1983 El Niño (Figure 5a and c), even though the eastward current anomaly during the former was much stronger (Figure $4 \mathrm{c}$ ). The zonal advection related to the eastward current anomaly is represented by $-u^{\prime} \frac{\partial \bar{T}}{\partial x}$. During the $2015 / 2016$ event, the magnitude of this term was comparable to that of 1997/1998 and was much larger than that of 1982/1983 (Z1 in Figure 6), indicating the strong positive zonal advection feedback during the 1997/1998 and 2015/2016 El Niño events. However, the other two terms related to the zonal advection $\left(-u^{\prime} \frac{\partial T^{\prime}}{\partial x}\right.$ and $\left.\bar{u} \frac{\partial T^{\prime}}{\partial x}\right)$ had much larger negative contributions during the 2015/2016 event as compared to the 1982/1983 event (Z2 and Z3 in Figure 6). The reason is twofold. First,

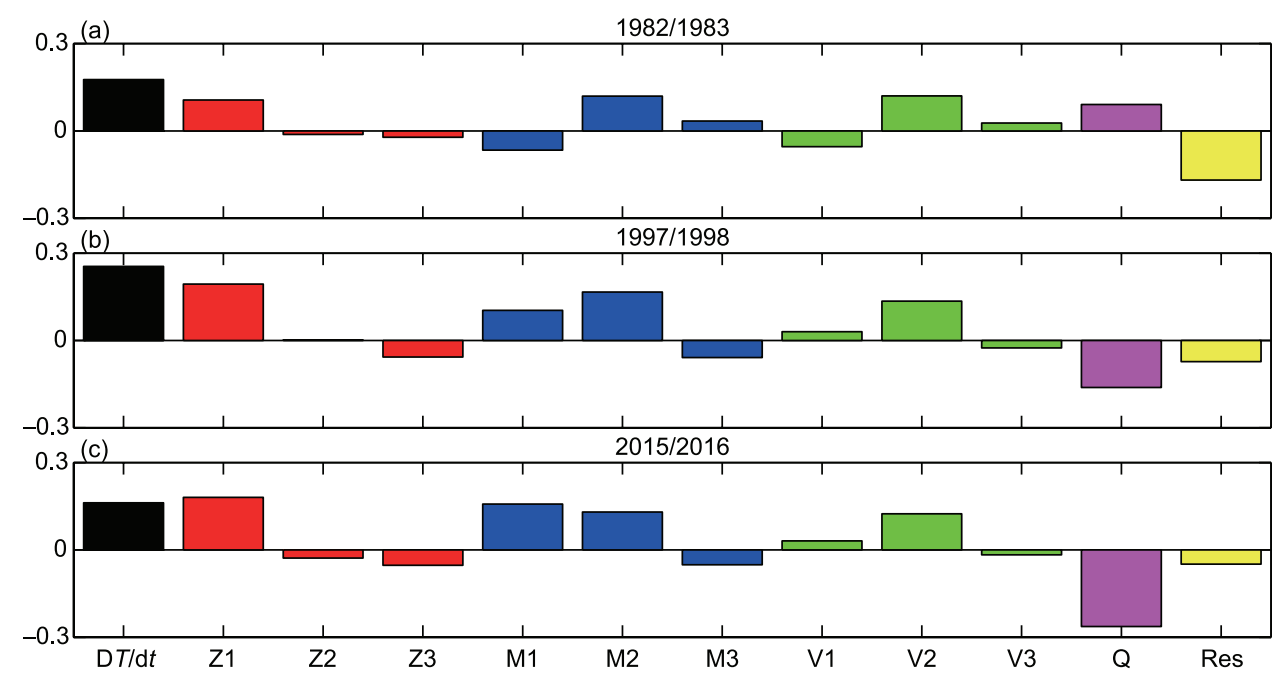

Figure 6 Surface-layer heat budgets in NINO3.4 region for (a) 1982/1983, (b) 1997/1998, and (c) 2015/2016 E1 Niño events. Black, purple, and yellow are the total tendency, surface heating, and residual term, respectively. Red, blue, and green bars denote zonal, meridional, and vertical advection, respectively. Details are given in the text. The units of all terms are ${ }^{\circ} \mathrm{C} /$ month. The budget is averaged over the region and over the El Niño year (from January to December). 
a strong warming occurred in early 2015 in the central equatorial Pacific (Stage 5), making the term $\frac{\partial T^{\prime}}{\partial x}$ negative. As the climatological zonal current was negative (westward), the term $-\bar{u} \frac{\partial T^{\prime}}{\partial x}$ would decrease the positive SST anomaly in the NINO3.4 region. In contrast, this term played a less significant role in suppressing the SST anomaly during the $1982 / 1983$ and 1997/1998 El Niño events because the early warming in the central equatorial Pacific was not as strong as for the 2015/2016 event. Second, as mentioned above, the eastward current anomalies during the 1997/1998 and $2015 / 2016$ events were much stronger than that during the $1982 / 1983$ El Niño, therefore the term $-u^{\prime} \frac{\partial T^{\prime}}{\partial x}$ played a more important role in suppressing the positive SST anomaly during the $1997 / 1998$ and 2015/2016 events.

\section{Effects of upper ocean heat content and WWB on El Niño}

The upper ocean heat content did not show significant anomaly during the development of the 2015/2016 El Niño (Figure $4 \mathrm{~b}$ ), but there were a large amount of WWBs (Figure $2 \mathrm{~b}$ ), leading to strong eastward current anomalies (Figure $4 \mathrm{c}$ ). The 5-month running WWB Wind Measure index is shown in Figure 7a for the 1982/1983, 1997/1998, and 2015/2016 El Niño events. It is clear that the WWB Wind Measure was much greater during the 1997/1998 and 2015/2016 El
Niño events than during the 1982/1983 El Niño. Figure $7 b$ presents the non-WWB Wind Measure index, which is defined as the integration of the surface wind anomalies not recognized as WWBs over the equatorial Pacific during the three extreme events. Thus the non-WWB Wind Measure index represents the low-frequency part of the surface wind related to the Bjerknes positive feedback. As shown, the non-WWB Wind Measure index evolved in a similar manner during the three events. Therefore, the main difference in the surface wind anomaly among the three extreme El Niño events was the absence of significant WWBs during 1982/1983 event, which obviously was responsible for the weak eastward current anomaly during that event. In general, it appears that the equatorial upper ocean heat content variation was the dominant process in the development of the 1982/1983 El Niño, the WWB-driven zonal advection was the essential process for the 2015/2016 El Niño, and both of these processes were important for the 1997/1998 El Niño.

To further assess the role of the upper ocean heat content variation in ENSO, Figure 8 shows a scatterplot of the WWV anomaly against the NINO3.4 SST anomaly for all ENSO events since 1980. It is clear that the variation of the upper ocean heat content indeed played an important role in ENSO, as El Niño events were mostly associated with positive WWV anomaly and La Niña events were mostly associated with negative WWV anomaly. The correlation between the WWV anomaly and the NINO3.4 SST anomaly was 0.716 and was significant at the $99 \%$ confidence level. Nonetheless, there were a couple of El Niño events (in 1994/1995 and 1987/
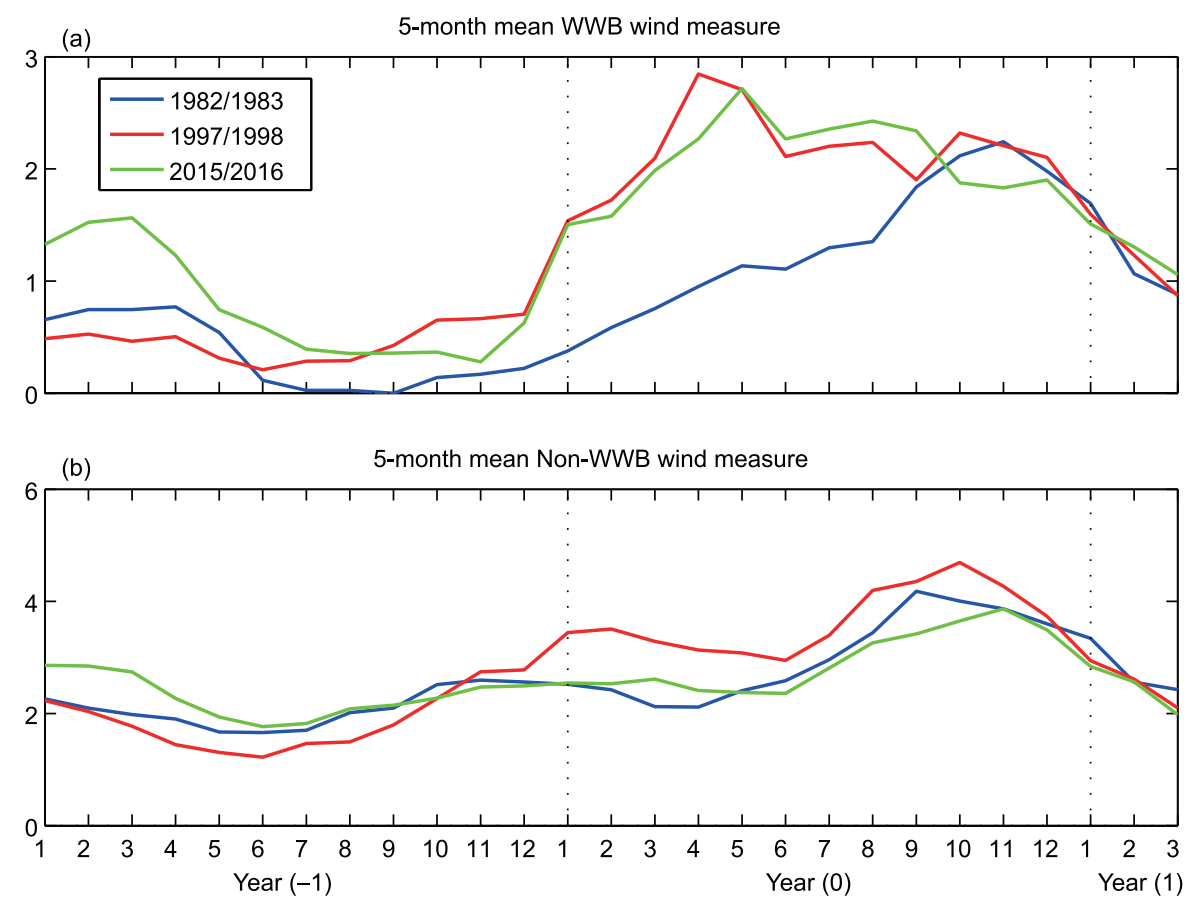

Figure 7 (a) WWB Wind Measure and (b) non-WWB Wind Measure indices during 1982/1983 (blue lines), $1997 / 1998$ (red lines), and 2015/2016 (green lines) extreme El Niño events. Unit is $10^{6} \mathrm{~m}$. Quantities shown are 5-month running means. 


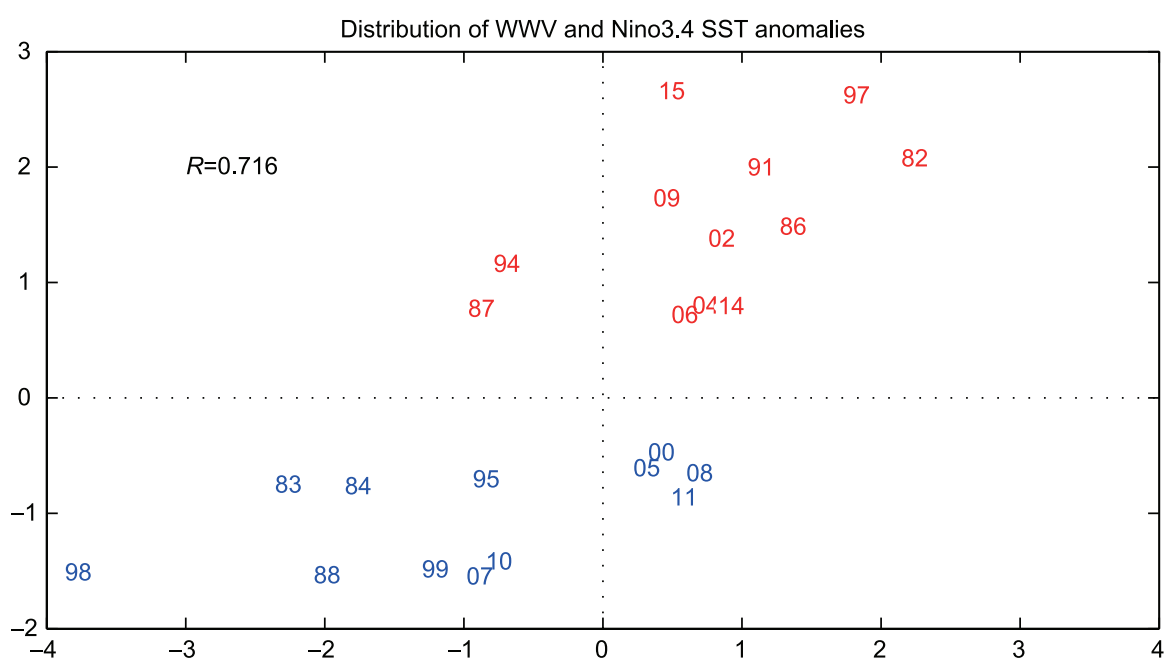

Figure 8 Scatter plots of WWV anomaly $\left(10^{14} \mathrm{~m}^{3}\right)$ and NINO3.4 SST anomaly $\left({ }^{\circ} \mathrm{C}\right)$ in El Niño years (red numbers) and La Niña years (blue numbers). WWV anomalies are averaged over an El Niño (La Niña) year, and NINO3.4 SST anomalies are averaged over DJF season. $R$ denotes the correlation coefficient.

1988) that occurred when the WWV anomalies were negative, and there were a few La Niña events (in 2000/2001, 2005/2006, 2008/2009, and 2011/2012) that occurred when the WWV anomalies were positive. This suggests that the upper ocean heat content alone is not sufficient for predicting whether an El Niño or La Niña would occur. Moreover, it is difficult to relate the magnitude of an ENSO event to the magnitude of the WWV anomaly. For example, the anomalous WWV during the extreme 2015/2016 El Niño was very small. The magnitude of La Niña events was even more insensitive to the magnitude of the WWV anomaly.

Figure 9 shows a scatterplot of the WWB Wind Measure index and the NINO3.4 SST anomaly for all ENSO events since 1980. The two variables have a correlation of 0.836 , significant at the $99 \%$ confidence level. Unlike the insensitivity of the NINO3.4 index to the magnitude of the WWV anomaly, there was a distinct separation between El Niño and La Niña in terms of the magnitude of the WWB Wind Measure index. That is, all El Niño events occurred when the WWB Wind Measure index was above a $2.0 \times 10^{6} \mathrm{~m}$ threshold, whereas most La Niña events occurred when the WWB Wind Measure index was below the threshold. The only exception was the 1984/1985 La Niña, which was associated with a WWB Wind Measure index above the threshold. During the 1997/1998 and 2015/2016 extreme El Niño events, the WWB Wind Measure index was extremely high, but the WWV anomaly during the 2015/2016 event was not far above zero (Figure 8). Our results indicated that an extreme El Niño

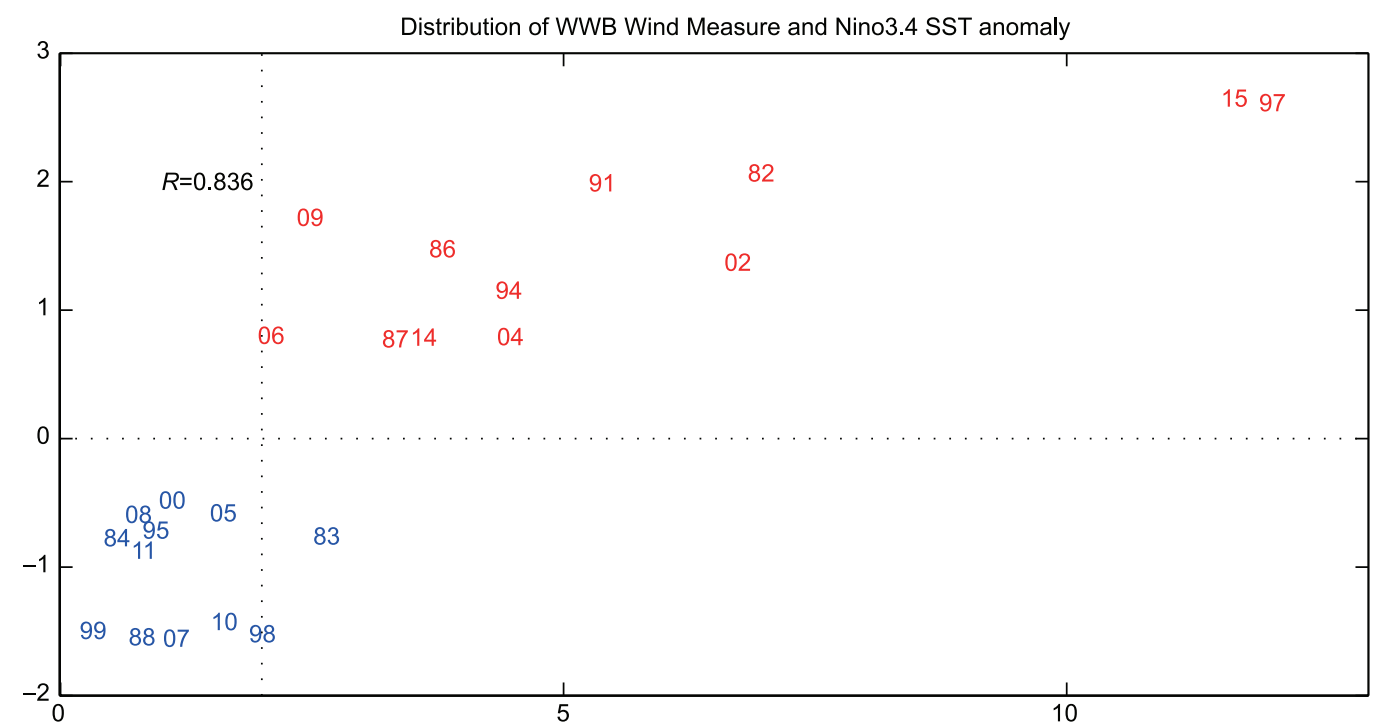

Figure 9 Scatter plots of WWB Wind Measure $\left(10^{6} \mathrm{~m}\right)$ and NINO3.4 SST anamaly $\left({ }^{\circ} \mathrm{C}\right)$ in El Niño years (red numbers) and La Niña years (blue numbers). WWB Wind Measure is averaged over an El Niño (La Niña) year, and NINO3.4 SST anomalies are averaged over DJF season. $R$ denotes the correlation coefficient. 
could be induced by strong and congregated WWBs even if the upper ocean heat content was close to neutral. However, like the WWV anomaly, the WWB Wind Measure index is not sufficient for ENSO prediction.

It was worth noting that the partial correlation between the WWV anomaly and the NINO3.4 index, while holding the WWB Wind Measure index fixed, is 0.801; and the partial correlation between the WWB Wind Measure index and the NINO3.4 index, while holding the WWV anomaly fixed, is 0.640 . Conversely, the partial correlation between the WWV anomaly and the WWB Wind Measure index, while holding the NINO3.4 index fixed, is -0.345 . All these partial correlations are significant at the $95 \%$ confidence level. These results indicate that both WWB and WWV can significantly and independently influence ENSO, while the two of them are not positively correlated. Therefore, it is necessary to include WWB into the theoretical framework of ENSO, and to improve the dynamical interpretation of ENSO which traditionally only consider the effects of WWV. Taking both WWB and WWV into account may enhance our ability to forecast the occurrence and the intensity of ENSO events.

\section{Discussion and conclusion}

The 2015/2016 El Niño was one of the strongest El Niño events in history, and this strong event was preceded by a weak El Niño in 2014. Using the daily NCEP2 surface wind reanalysis and the NCEP-GODAS ocean reanalysis, this study have systematically analyzed the dynamical processes responsible for the genesis of these events. The weak 2014 El Niño had two warming phases, the spring-summer warming was mainly produced by anomalous zonal advection and downwelling Kelvin waves driven by WWBs, and the autumn-winter warming was mainly produced by anomalous meridional advection, surface heating as well as downwelling Kelvin waves. The 2015/2016 extreme El Niño, on the other hand, was primarily a result of sustained zonal advection and downwelling Kelvin waves driven by a series of WWBs, with enhancement from the Bjerknes positive feedback. The vast difference between these two El Niño events was mainly caused by the much more WWBs in 2015 as compared to 2014.

As compared to the 1982/1983 and 1997/1998 extreme El Niño events, the 2015/2016 El Niño exhibited some distinctive characteristics. First, unlike 1982 and 1997, the upper ocean heat content was near normal in 2015 , suggesting that recharging the equatorial upper ocean heat content was not a necessary condition for the development of an extreme El Niño. Apparently, this cannot be explained by the classic ENSO theory. Second, there were strong and congregant WWBs throughout 2015, with a total effect comparable to 1997 and much larger than 1982. This suggests that an extreme El Niño could be induced by a large amount of strong
WWBs (2015/2016 El Niño), or by a very large anomaly of equatorial upper ocean heat content (1982/1983 El Niño), or by a combination of the two (1997/1998 El Niño). Finally, the warming center of the 2015/2016 El Niño was shifted westward as compared to the 1982/1983 and 1997/1998 El Niño events. In other words, the maximum positive SST anomaly did not appear near the South American coast where the thermocline feedback should be the strongest. This was probably due to the relatively weak thermocline depth anomaly in the eastern equatorial Pacific in 2015.

While extreme El Niño events rarely occurred in history, they had extraordinary impacts on the global climate (Pearcy and Schoener, 1987; Changnon, 2000; Zhan et al., 2016). Previous studies suggested that the genesis of an extreme El Niño could be attributed to the effects from nonlinear convection (Hoerling et al., 1997; Kang and Kug, 2002), biological feedback (Timmermann and Jin, 2002; Marzeion et al., 2005), tropical instability waves (Vialard et al., 2001), and the feedback form the Indian Ocean (Okumura and Deser, 2010). However, as found in this study, the genesis and development of extreme El Niño events are closely associated with WWB and the variation of the upper ocean heat content. As the NINO3.4 index is highly and positively correlated to the WWB Wind Measure index and the upper ocean heat content index, it is possible to combine these indices to develop a method for ENSO forecasting.

Predicting extreme El Niño is undoubtedly a primary focus of ENSO research. Classic theories suggest that ENSO prediction is mainly limited by the nonlinear growth of initial errors (Chen et al., 1995, 2004; Mu et al., 2007; Peng et al., 2015; Song et al., 2015; Zheng et al., 2015), and that the potential predictability of ENSO should be on the order of years. However, our results indicate that WWB play a very important role in ENSO development. Taking the effects of WWB into account, the predictability of ENSO should depend on both semi-stochastic process and initial conditions, and WWB must be realistically represented in ENSO prediction models. However, the mechanism of WWB is still unclear. It was suggested that WWB is associated with the Madden Julian Oscillation, cold surge, and the equatorial convective Rossby wave (Keen, 1982; Chen et al., 1996; Yu and Rienecker, 1998; Puy et al., 2016), but none of these processes was convincingly verified over a large number of WWBs (Oh et al., 2015), and they cannot explain why the number of easterly wind bursts is far less than that of WWBs (Seiki and Takayabu, 2007). To improve our ability to predict ENSO, especially extreme El Niño events, we need to understand the genesis and predictability of WWB. This is our ongoing work and will be reported on another occasion.

Acknowledgements This study was supported by the National Natural Science Foundation of China (Grant Nos. 41690121, 41690124, 41690120, 41506025 \& 41621064), the National Program on Global 
Change and Air-Sea Interaction (Grant Nos. GASI-IPOVAI-04 \& GASI-IPOVAI-06), and the Zhejiang Provincial Natural Science Foundation of China (Grant No. LQ15D060004).

\section{References}

An S I, Jin F F. 2001. Collective role of thermocline and zonal advective feedbacks in the ENSO mode. J Clim, 14: 3421-3432

Ashok K, Behera S K, Rao S A, Weng H, Yamagata T. 2007. El Niño Modoki and its possible teleconnection. J Geophys Res, 112: C11007

Bjerknes J. 1969. Atmospheric teleconnections from the equatorial Pacific. Mon Weather Rev, 97: 163-172

Changnon S A. 2000. El Niño, 1997-1998: The Climate Event of the Century. New York: Oxford University Press. 232

Chen D, Cane M A. 2008. El Niño prediction and predictability. J Comp Phys, 227: 3625-3640

Chen D, Cane M A, Kaplan A, Zebiak S E, Huang D. 2004. Predictability of El Niño over the past 148 years. Nature, 428: 733-736

Chen D, Lian T, Fu C, Cane M A, Tang Y, Murtugudde R, Song X, Wu Q, Zhou L. 2015. Strong influence of westerly wind bursts on El Niño diversity. Nat Geosci, 8: 339-345

Chen D, Zebiak S E, Busalacchi A J, Cane M A. 1995. An improved procedure for EI Nino forecasting: Implications for predictability. Science, 269: 1699-1702

Chen S S, Houze Jr R A, Mapes B E. 1996. Multiscale variability of deep convection in realation to large-scale circulation in TOGA COARE. J Atmos Sci, 53: 1380-1409

Fedorov A V, Hu S, Lengaigne M, Guilyardi E. 2015. The impact of westerly wind bursts and ocean initial state on the development, and diversity of El Niño events. Clim Dyn, 44: 1381-1401

Fu C, Diaz H F, Fletcher J O. 1986. Characteristics of the response of sea surface temperature in the central Pacific associated with warm episodes of the southern oscillation. Mon Weather Rev, 114: 1716-1739

Fu Y F, Huang R H. 1997. Impacts of westerly anomalies over East Asian on westerly burst over the western tropical and the occurrence of ENSO events (in Chinese). Sci Atmos Sin, 4: 485-492

Harrison D E, Vecchi G A. 1997. Westerly wind events in the tropical Pacific, 1986-95. J Clim, 10: 3131-3156

Hoerling M P, Kumar A, Zhong M. 1997. El Niño, La Niña, and the nonlinearity of their teleconnections. J Clim, 10: 1769-1786

Hu S, Fedorov A V. 2016. Exceptionally strong easterly wind burst stalling El Niño of 2014. Proc Natl Acad Sci USA, 113: 2005-2010

Jin F F. 1997a. An equatorial ocean recharge paradigm for ENSO. Part I: Conceptual mdel. J Atmos Sci, 54: 811-829

Jin F F. 1997b. An equatorial ocean recharge paradigm for ENSO. Part II: A stripped-down coupled model. J Atmos Sci, 54: 830-847

Jin F F, An S I, Timmermann A, Zhao J. 2003. Strong El Niño events and nonlinear dynamical heating. Geophys Res Lett, 30: 1120

Kanamitsu M, Ebisuzaki W, Woollen J, Yang S K, Hnilo J J, Fiorino M, Potter G L. 2002. NCEP-DOE AMIP-II reanalysis (R-2). Bull Amer Meteorol Soc, 83: 1631-1643

Kang I S, Kug J S. 2002. El Niño and La Niña sea surface temperature anomalies: Asymmetry characteristics associated with their wind stress anomalies. J Geophys Res, 107: 4372-4381

Keen R A. 1982. The role of cross-equatorial tropical cyclone pirs in the southern oscillation. Mon Weather Rev, 110: 1405-1416

Kug J S, Jin F F, An S I. 2009. Two tpes of El Niño events: Cold tngue El Niño and warm pool El Niño. J Clim, 22: 1499-1515

Larkin N K, Harrison D E. 2005. On the definition of E1 Niño and associated seasonal average U.S. weather anomalies. Geophys Res Lett, 32: L13705

Li J, Liu B, Li J, Mao J. 2015. A comparative study on the dominant factors responsible for the weaker-than-expected El Niño event in 2014. Adv Atmos Sci, 32: 1381-1390
Lian T, Chen D. 2012. An evaluation of rotated EOF analysis and its application to tropical Pacific SST vriability. J Clim, 25: 5361-5373

Lian T, Chen D K, Tang Y M, Jin B G. 2014a. A theoretical investigation of the tropical Indo-Pacific tripole mode. Sci China Earth Sci, 57: 174-188

Lian T, Chen D, Tang Y, Wu Q. 2014b. Effects of westerly wind bursts on El Niño: A new perspective. Geophys Res Lett, 41: 3522-3527

Lian T, Tang Y M. 2017. Frequency-specified EOF analysis and its application to Pacific decadal oscillation. Sci China Earth Sci, 60: 341-347

Liu B Q, Li J Y, Mao J Y, Ren R C, Liu Q M. 2015. Possible mechanism for the development and suspending of El Niño event in 2014 (in Chinese). Chin Sci Bull, 60: 2133-2148

Lee T, McPhaden M J. 2010. Increasing intensity of El Niño in the centralequatorial Pacific. Geophys Res Lett, 37: L14603

Marzeion B, Timmermann A, Murtugudde R, Jin F F. 2005. Biophysical feedbacks in the tropical Pacific. J Clim, 18: 58-70

McPhaden M J. 1999. Genesis and Evolution of the 1997-98 El Nino. Science, 283: 950-954

McPhaden M J. 2004. Evolution of the 2002/03 El Niño. Bull Amer Meteorol Soc, 85: 677-695

McPhaden M J, Bahr F, Du Penhoat Y, Firing E, Hayes S P, Niiler P P, Richardson P L, Toole J M. 1992. The response of the western equatorial Pacific Ocean to westerly wind bursts during November 1989 to January 1990. J Geophys Res, 97: 14289

McPhaden M J, Freitag H P, Hayes S P, Taft B A, Chen Z, Wyrtki K. 1988. The response of the equatorial Pacific Ocean to a westerly wind burst in May 1986. J Geophys Res, 93: 10589

Meinen C S, McPhaden M J. 2000. Observations of Warm water volume changes in the euatorial Pacific and Their relationship to El Niño and La Niña. J Clim, 13: 3551-3559

Menkes C E, Lengaigne M, Vialard J, Puy M, Marchesiello P, Cravatte S, Cambon G. 2014. About the role of Westerly Wind Events in the possible development of an El Niño in 2014. Geophys Res Lett, 41: 6476-6483

Min Q, Su J, Zhang R, Rong X. 2015. What hindered the El Niño pattern in 2014? Geophys Res Lett, 42: 6762-6770

$\mathrm{Mu}$ M, Xu H, Duan W. 2007. A kind of initial errors related to "spring predictability barrier" for El Niño events in Zebiak-Cane model. Geophys Res Lett, 34: L03709

Neelin J D, Battisti D S, Hirst A C, Jin F F, Wakata Y, Yamagata T, Zebiak S E. 1998. ENSO theory. J Geophys Res, 103: 14261-14290

Oh J H, Jiang X, Waliser D E, Moncrieff M W, Johnson R H, Ciesielski P. 2015. A momentum budget analysis of westerly wind events associated with the Madden-Julian oscillation during DYNAMO. J Atmos Sci, 72: 3780-3799

Okumura Y M, Deser C. 2010. Asymmetry in the dration of El Niño and La Niña. J Clim, 23: 5826-5843

Pearcy W G, Schoener A. 1987. Changes in the marine biota coincident with the 1982-1983 El Niño in the northeastern Subarctic Pacific Ocean. J Geophys Res, 92: 14417-14428

Peng Y, Song J, Xiang J, Sun C. 2015. Impact of observational MJO forcing on ENSO predictability in the Zebiak-Cane model: Part I. Effect on the maximum prediction error. Acta Oceanol Sin, 34: 39-45

Philander S G H. 1990. El Niño, La Nina, and the Southern Oscillation. London: Academic Press. 293

Puy M, Vialard J, Lengaigne M, Guilyardi E. 2016. Modulation of equatorial Pacific westerly/easterly wind events by the Madden-Julian oscillation and convectively-coupled Rossby waves. Clim Dyn, 46: 2155-2178

Rasmusson E M, Carpenter T H. 1982. Variations in tropical sea surface temperature and surface wind fields associated with the southern oscillation/El Niño. Mon Weather Rev, 110: 354-384

Rong X, Zhang R, Li T, Su J. 2011. Upscale feedback of high-frequency winds to ENSO. Q J R Meteorol Soc, 137: 894-907

Saha S, Nadiga S, Thiaw C, Wang J, Wang W, Zhang Q, Van den Dool H M, Pan H L, Moorthi S, Behringer D, Stokes D, Peña M, Lord S, White G, Ebisuzaki W, Peng P, Xie P. 2006. The NCEP climate forecast system. J 
Clim, 19: 3483-3517

Seiki A, Takayabu Y N. 2007. Westerly wind bursts and their relationship with intraseasonal variations and ENSO. Part I: Statistics. Mon Weather Rev, 135: 3325-3345

Song Z, Shu Q, Bao Y, Yin X, Qiao F. 2015. The prediction on the 2015/16 El Niño event from the perspective of FIO-ESM. Acta Oceanol Sin, 34: $67-71$

Sun R, Ling Z, Chen C, Yan Y. 2015. Interannual variability of thermal front west of Luzon Island in boreal winter. Acta Oceanol Sin, 34: 102-108

Timmermann A, Jin F F. 2002. Phytoplankton influences on tropical climate. Geophys Res Lett, 29: 19-1-19-4

Vecchi G A, Harrison D E. 2000. Tropical Pacific sea surface temperature anomalies, El Niño, and equatorial westerly wind events. J Clim, 13: $1814-1830$

Vialard J, Menkes C, Boulanger J P, Delecluse P, Guilyardi E, McPhaden M J, Madec G. 2001. A model study of oceanic mechanisms affecting equatorial Pacific Sea surface temperature during the 1997-98 El Niño. J Phys Oceanogr, 31: 1649-1675

Wang H, Liu K, Qi D, Gao Z, Fan W, Zhang Z, Wang G. 2016. Causes of seasonal sea level anomalies in the coastal region of the East China Sea. Acta Oceanol Sin, 35: 21-29

Yan B L, Zhang R H. 2002. The role of atmosphere climate basic state in the formation of westerly over the equatorial Pacific (in Chinese). Acta Oceanol Sin, 24: 39-50

Yu L, Rienecker M M. 1998. Evidence of an extratropical atmospheric influence during the onset of the 1997-98 El Niño. Geophys Res Lett, 25: 3537-3540

Zhan R F, Ding Y H, Wu L G, Lei X T. 2016. Role of ENSO in the interannual relationship between Tibetan Plateau winter snow cover and Northwest Pacific tropical cyclone genesis frequency. Sci China Earth Sci, 59: 2009-2021

Zhang C, Li S L. 2015. Why is the El Niño event during the 2014 winter not a strong one? (in Chinese) Chin Sci Bull, 60: 1941-1951

Zhang X M, Chen C, Lian T, Chen D K. 2017. Spatiotemporal modes of global sea surface temperature variability. Sci China Earth Sci, 60: $508-516$

Zheng F, Wang H, Wan L. 2015. Roles of initial ocean states on predicting the 2002/03 central Pacific El Niño. Acta Oceanol Sin, 34: 72-79

Open Access This article is distributed under the terms of the Creative Commons Attribution License which permits any use, distribution, and reproduction in any medium, provided the original author(s) and source are credited. 